\title{
Communicating Astronomy with the Public (Youth) as the Gateway to Development
}

\author{
Dennis R. Crabtree
}

National Research Council Canada; email: Dennis.Crabtree@nrc.ca

\begin{abstract}
Astronomy has a unique ability to excite and stimulate the curiosity of children. Because of this, society can use astronomy as a gateway to lead children on a path towards future learning of science and technology, and potentially to careers in these areas.
\end{abstract}

Keywords. miscellaneous

Children have a natural curiosity about the world. This extends, to varying degrees, to later in life for most people. This curiosity makes youth open to new ideas and experiences and is an ideal time to expose them to the wonders of the Universe.

At this early stage of their life, children build knowledge, life skills and, perhaps most importantly, attitudes that will be with them for life. Evidence shows that this begins well before a child begins formal education $\dagger$. It is important to engage young children in exploring and learning about the natural, physical and technological world.

One must remember that not all children will end up in science or technological careers. Think of a world without poets, musicians, artists, and yes, even lawyers. The goal is to ensure that children are exposed to the widest possible gamut of experiences and activities to ensure they will find their calling in life.

Astronomy is a powerful force to excite youth about science and technology. When combined with informal education's ability to inform, astronomy outreach has a unique ability to exite and inform youth.

It is important to expose children as often as possible to astronomy-related activities so the level of excitement in the natural world is maintained. Children's families are very important factors in determining a child's path in life. The Astronomical Society of the Pacific's Family Astro program $\ddagger$ is excellent for helping parents get involved their child's science training and to share in the excitement.

Astronomy outreach for youth - Excite and Inform

$\dagger$ Deadly Moons - Ireland http://unawe.org/resources/education/deadly_moons_guide_158/ $\ddagger$ http://www.astrosociety.org/education/family.html 